\title{
Characteristics and moisture sources of the stable isotopes in precipitation in the monsoon marginal region of north-central China
}

\author{
Yiping Zhang ${ }^{1}$, Junliang $\mathrm{Xu}^{1}$, Yafei $\mathrm{Yan}^{1}$, Wei $\mathrm{Su}^{1}$, Zhiqiang $\mathrm{Shi}^{1}$, and Lei Zhu ${ }^{1}$ \\ ${ }^{1}$ Henan University of Science and Technology
}

May 19, 2021

\begin{abstract}
The stable hydrogen and oxygen isotopes in precipitation ( $\delta \mathrm{D}$ and $\delta 18 \mathrm{O}$, respectively) are important source signatures for understanding the hydrological cycle and paleoclimatic reconstruction. In this study, 32 precipitation samples were collected from April to October 2014 at the Luya Mountain summit, a representative site in the monsoon marginal area of north-central China. The isotopic signatures of precipitation exhibited strong seasonal variations ranging from -185.61and -25.51relatively higher in August and lower in September. The local meteoric water line was $\delta \mathrm{D}=(7.95 \pm 0.16) \delta 18 \mathrm{O}+(15.79 \pm 1.77)(\mathrm{R} 2=0.988$, $\mathrm{N}=32, \mathrm{p}<0.001)$, which had a similar slope but higher intercept than that of the global meteoric water line, indicating that the precipitation in this area is mainly sourced from the ocean surface transported via monsoons. Additionally, the secondary evaporated water by continental recycled moisture was identified by the significantly higher deuterium excess value (16.09via the Hybrid Single-Particle Lagrangian Integrated Trajectory model indicated seasonal moisture transport changes in the studied monsoonal marginal region, in which the main moisture sources were the Westerly winds in April, the Pacific Ocean in July, and the Indian Ocean in September. Secondary evaporated water from the alpine ecosystem may also influence the local atmospheric water cycle throughout the year. Positive temperature-isotopic signature effect $(\delta \mathrm{D}$ and $\delta 18 \mathrm{O})$ was observed in the cold season (before mid-May); however, the precipitation amount effect was observed in the monsoon season from June to August, and both effects became vague across the entire period. These findings suggest that the stable isotope compositions of precipitation can be utilized to determine the moisture sources in the monsoon marginal region of north-central China and potentially be utilized to reconstruct the precipitation signals in this region.
\end{abstract}

\section{Hosted file}

0-mianbody-no Fig.docx available at https://authorea.com/users/414607/articles/522610characteristics-and-moisture-sources-of-the-stable-isotopes-in-precipitation-in-themonsoon-marginal-region-of-north-central-china 

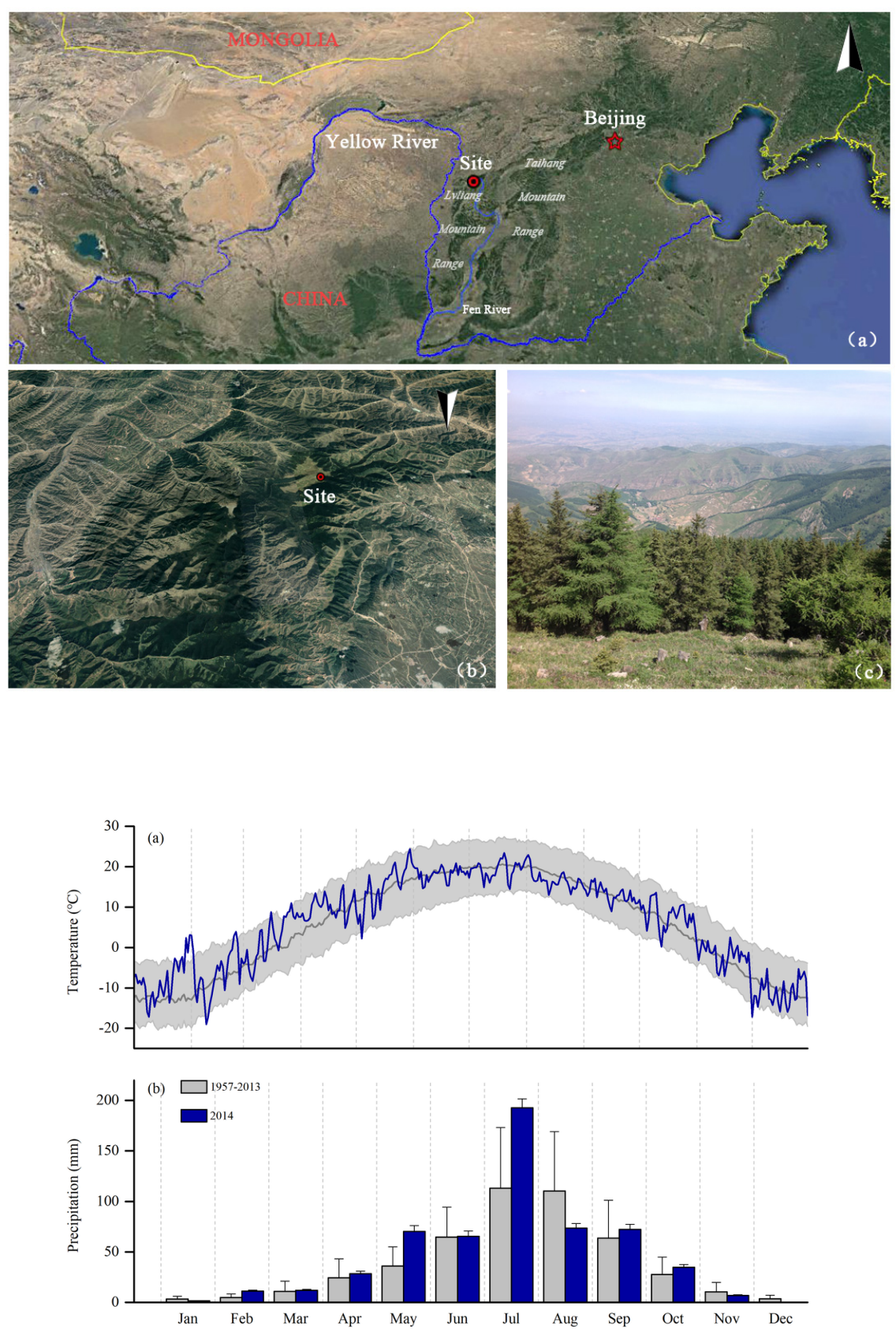
$\circ d$-excess $\nabla \delta \mathrm{D} \triangle \delta^{18} \mathrm{O} \longrightarrow$ - Ta $\square \mathrm{P} \longrightarrow \mathrm{RH} \longrightarrow$ VPD

Before growing season Growing season After growing season

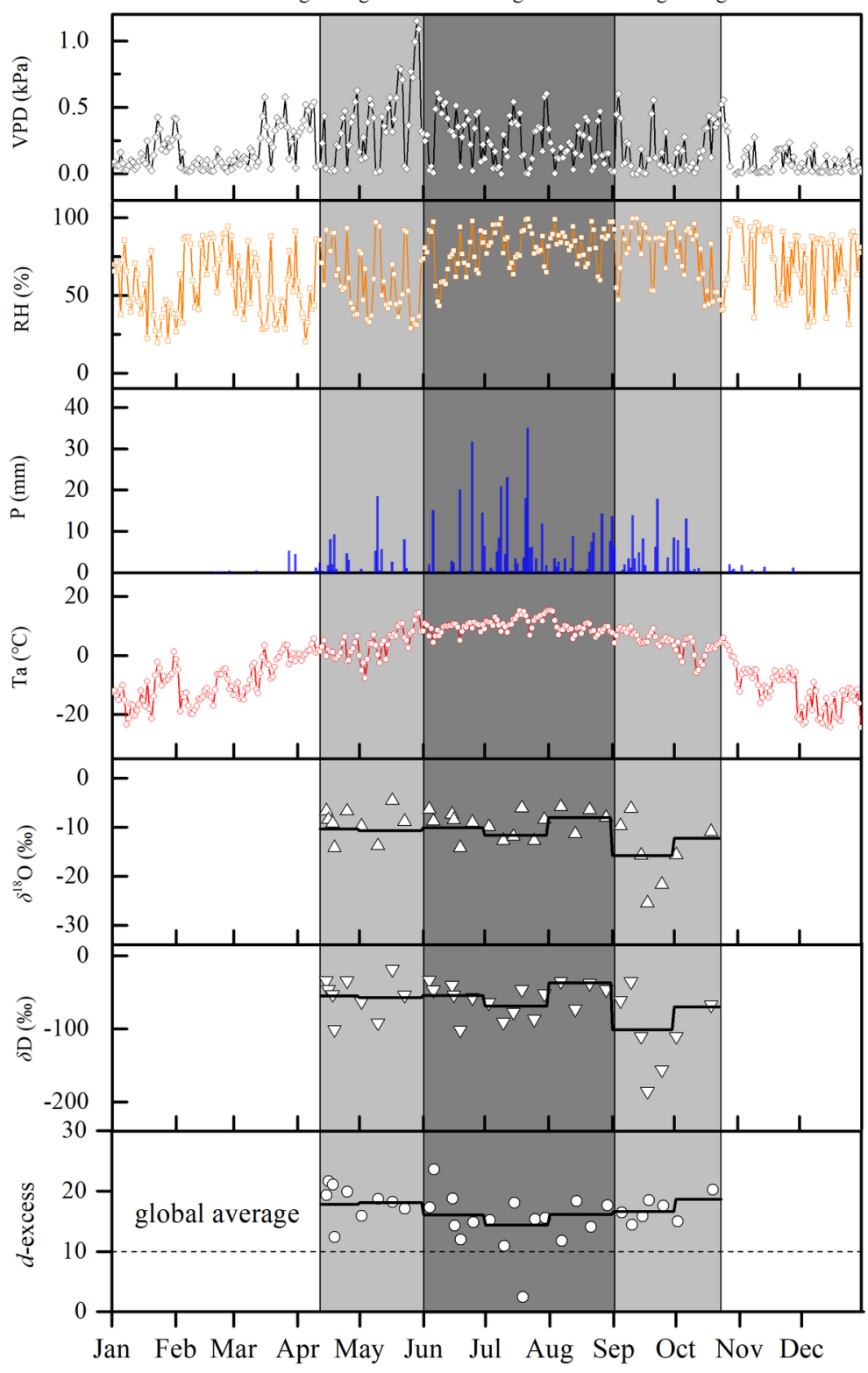



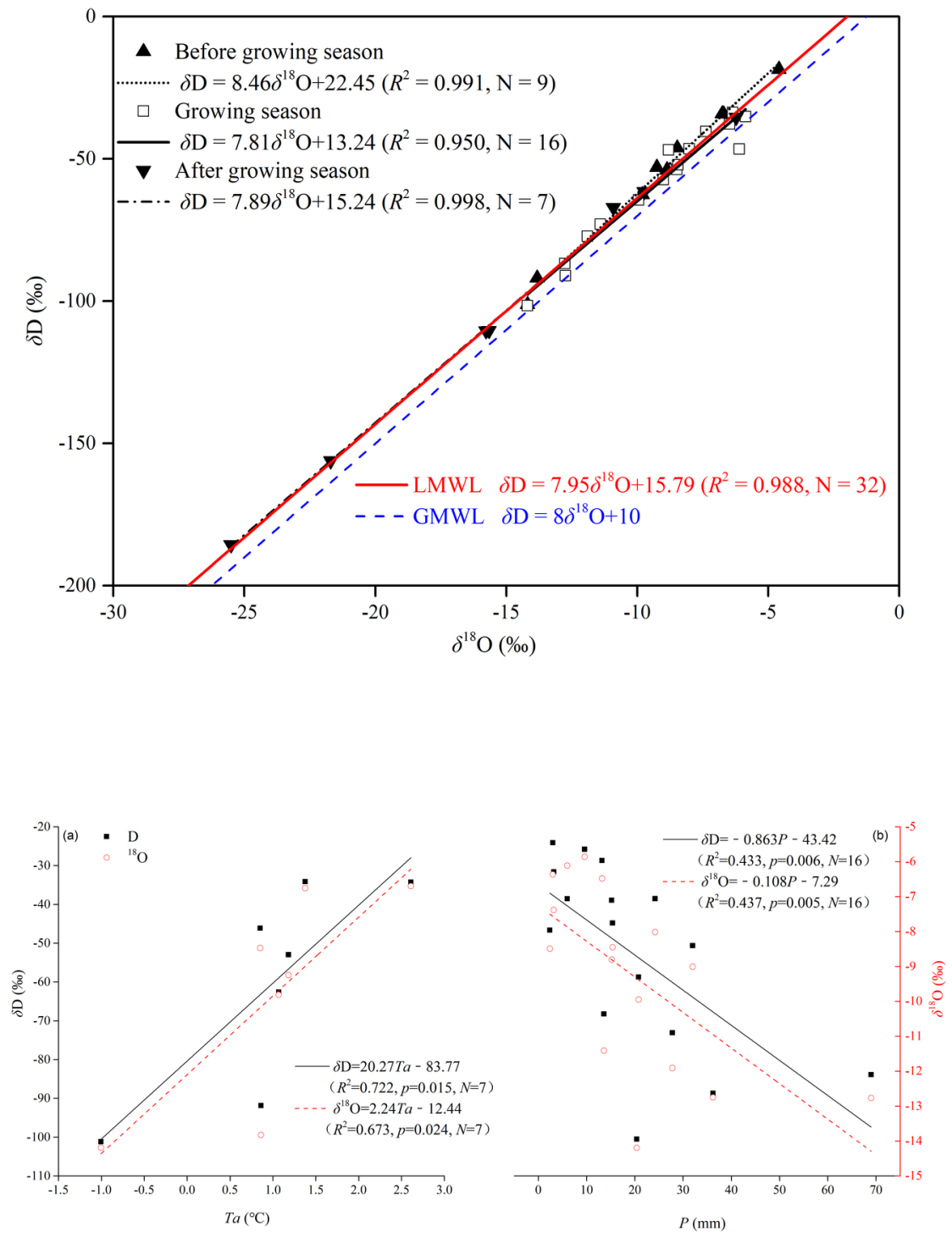

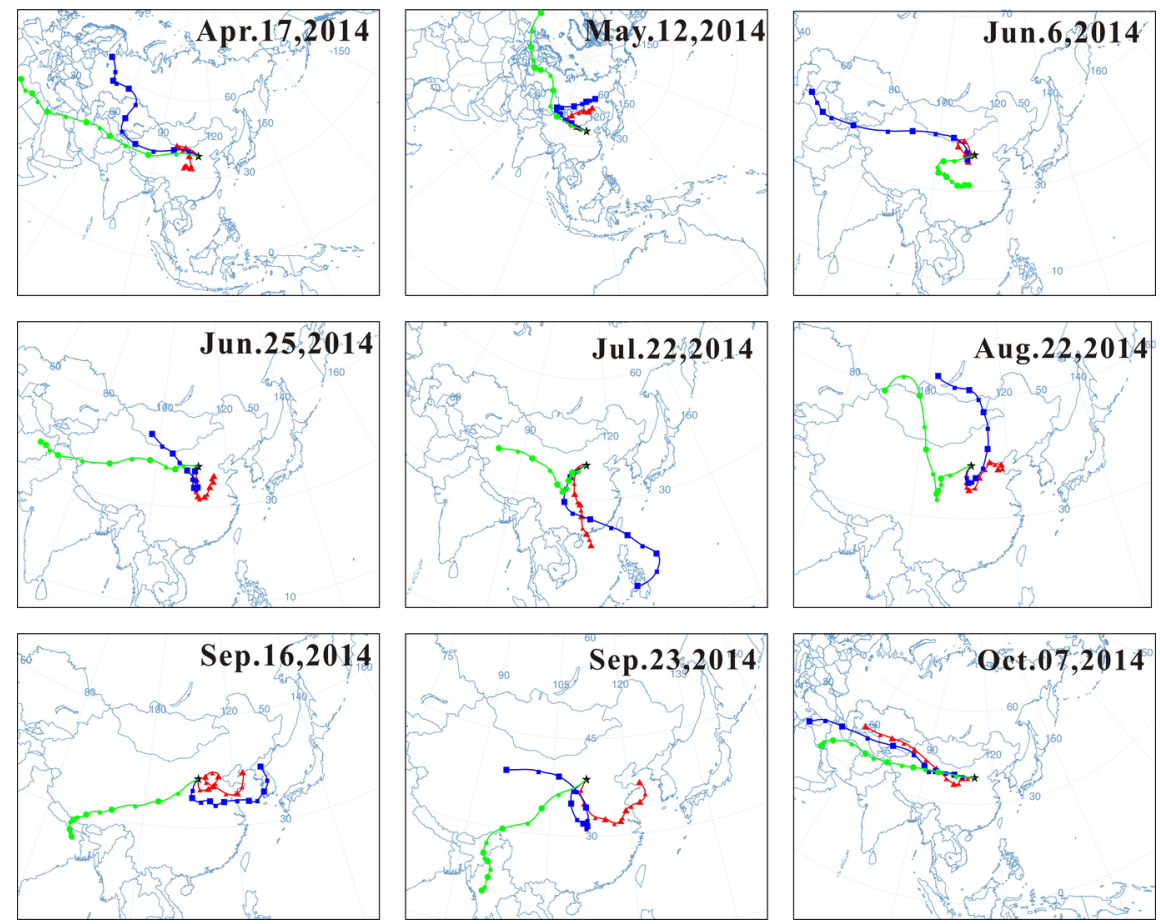

\section{Hosted file}

2-Tables.docx available at https ://authorea.com/users/414607/articles/522610-characteristicsand-moisture-sources-of-the-stable-isotopes-in-precipitation-in-the-monsoon-marginalregion-of-north-central-china 